\title{
The Relationship between Parent-Child Interactions and Prosocial Behavior among Fifth- and Sixth-grade Students: Gratitude as a Mediating Variable
}

\author{
Ho-Tang $\mathrm{Wu}^{1}$, Shu-Feng Tseng ${ }^{2}$, Pai-Lu Wu ${ }^{3, *}$, Chun-Miao Chen ${ }^{4}$ \\ ${ }^{1}$ Department of Education, National Kaohsiung Normal University, Taiwan \\ ${ }^{2}$ Department of Applied Foreign Language, Cheng-Shiu University, Taiwan \\ ${ }^{3}$ Center for Teacher Education, Cheng-Shiu University, Taiwan \\ ${ }^{4}$ Preschool, Hanmin Elementary School, Taiwan
}

Copyright $\bigcirc 2016$ by authors, all rights reserved. Authors agree that this article remains permanently open access under the terms of the Creative Commons Attribution License 4.0 International License

\begin{abstract}
Parent-child interaction, gratitude and prosocial behavior have a crucial impact on psychological development. According to our literature review, these three variables are positively related to one another. Therefore, the authors created a model that treats parent-child interaction as an exogenous variable, gratitude as a mediating variable, and prosocial behaviors as endogenous variables. To test this model, the authors administered the Parent-Child Interaction Scale, the Gratitude Scale, and the Prosocial Behavior Scale, which have good validity and reliability, to a total of 987 fifth- and sixth-grade students in Kaohsiung. In regard of gender, there were 521 males, occupying 52.8\%; 466 females, occupying $47.2 \%$. In respect with grade level, there were 482 grade- 5 students, occupying $48.8 \%$; 505 grade- 6 students, occupying $51.2 \%$. Based on an analysis of data using structural equation modeling (SEM), we reached the following conclusions: 1 There was a significant positive correlation between father-child and mother-child interactions; 2 . There was a significant positive correlation between parent-child interaction, gratitude, and prosocial behavior; 3. Gratitude mediated the relationship between parent-child interaction and prosocial behavior.
\end{abstract}

Keywords Gratitude, Parent-child Interaction, Prosocial Behavior

\section{Introduction}

\subsection{Research Motivations}

Parent-child interaction, gratitude, and prosocial behavior have a crucial impact on the psychological development of higher-level elementary school students. Specifically, parent-child interaction refers to the physical and psychological interaction between parents and their children (Gongla \& Thompson, 1987) [1], which deeply affects children's physical and psychological development (Jeon, Peterson, \& DeCoster, 2013) [2]. In physical development, parents act as a good role model by having a healthy diet and conducting physical activity (Pocock, Trivedi, Wills, Bunn, \& Magnusson, 2010) [3]. As for psychological development, intellectual functioning, creativity, psychological adjustment, and well-being are enhanced (Suldo \& Fefer, 2013) [4].

Regardless of eastern or western cultural traditions, gratitude functions as an important element. Western countries emphasize on Thanksgiving Day, which is influential to people in spite of its original intention for showing awe to God. On the other hand, Chinese have a long tradition for gratitude, such as "return a peach for receiving a plum", "Even the inch-long hearts of the grass demand ; repaying the spring sun's nurturing hand", and "repay water drop with fountain". In addition, in the ancient Confucianism, people proposed eight virtues, including loyality, dutifulness, benevolence, love, honest, justice, peace, and fair, and put "benevolence" and dutifulness as core behaviors (Wen, 1989) [5]. McCullough, Emmons, and Tsang (2002) [6] also pointed out that gratitude is a function of the perception of intentional benevolence. In Chinese culture, gratitude has become the fundamental value and faith, as well as the root moral principle (Zhang, 2008) [7].

Gratitude refers to being thankful for all the good things in life (Seligman, 2012) [8]. As Cicero once said, "Gratitude is not only the greatest of virtues, but the parent of all the others" (quoted from McCullough, Kilpatrick, Emmions, \& Larson, 2001) [9]. Therefore, Peterson and Seligman (2004) [10] believed that gratitude is a prosocial emotion and an important positive habit that contributes to a sound moral character, or as McCullough, Kimeldorf and Cohen(2008) [11] claimed that gratitude is a pleasant emotion, but it is different from simple happiness because gratitude is 
typically preceded by the perception that one has benefited from another person's generosity. In addition, gratitude plays a key role in establishing and maintaining social relationships (Bartlett, Condon, Cruz, Baumann, \& Desteno, 2012) [12]. It is also one of the seven elements of a successful child (the other six elements are grit, self-control, zest, social intelligence, optimism, and curiosity) (Tough, 2013) [13]. Furthermore, gratitude is positively related to life satisfaction, autonomy, environmental mastery, personal growth, purpose in life, self-acceptance (Lambert \& Veldorale-Brogan, 2013) [14], and psychological well-being (Wood, Joseph, \& Maltby, 2009) [15]. It can enrich the meaning of life, increase optimism, and enhance friendships, academic achievement, and trust (Gonzaga, Keltner, Londahl, \& Smith, 2001) [16] as well reduce children's disruptive (Lewis, 2011) [17] or defiant behaviors (Zisser \& Eyberg, 2010) [18].

Prosocial behavior, which involves caring for others, generosity, kindness, help, sharing, and comforting, makes people genuinely concerned about the well-being one another (Eisenberg \& Mussen, 1989) [19]. Both the Western and the Eastern are taught by parents and teachers to enjoy helping others in the family, school, and the varied environments. For Chinese, this is closely related to cultural traditions, for Chinese are taught that "helping others is the origin of happiness", "helping others as priority when people are in urgent need", "the virtuous people regard others as superior to themselves", "standing up against injustice", "helping others is a virtue". Prosocial behavior has important impact on children's psychological development, since it is a hallmark of social competence during childhood (Wentzel, 2014)[20] and has been related to peer relationships, motivation, and academic performance (Wentzel, 2005) [21]; positive adjustment at school (Wentzel, Baker \& Russell, 2009)[22]; and empathy, levels of moral reasoning, and affective functioning (Eisenberg, Morris, McDaniel, \& Spinrad, 2009)[23]. It can also influence the relationship between the impact of peer pressure and that of loneliness (Griese \& Buhs, 2014) [24] and has a mediating effect on the relationship between well-being/psychological need satisfaction and the satisfaction of psychological needs (Weinstein \& Ryan, 2010) [25].

In addition to their independent effects on physical and mental development, parent-child interaction, gratitude, and prosocial behavior are also correlated with one another. In terms of the relationship between parent-child interaction and gratitude, Seligman (2012) [8] proposed that gratitude starts at home. Gordon (2013) [26] also believed that parents can serve as role models for gratitude through their interactions with their children. Moreover, the empirical research conducted by Herschell, Calzada, Eyberg, and McNeil (2003) [27] found that parent-child interactions affect the prosocial behavior of children. Consequently, parent-child interaction influential to gratitude.

Additionally, gratitude affects prosocial behavior. As McCullough et al (2002) [6] find in the research that those with higher gratitude orientation have more positive emotions and higher life satisfaction, and less negative emotions such as depression, jealousy, and so on. It is more likely for such people to help and support others with sympathy and forgiveness. McCullough et al. (2001) [9] and McCullough, Kimeldorf and Cohen (2008) [28] all claim that gratitude is a motivator of prosocial behavior, and it motivates people to behave prosocially after obtaining benefits. Meanwhile, gratitude is also a reinforcement for prosocial behavior, because expression of gratitude increases the likelihood that benefactors will behave prosocially repeatedly in the future, as proven by Dunn and Schweitzer (2005) [29].

In respect with the research subject, prosocial behavior is known to emerge in the second year of life (Dunfield, Kuhlmeier, Connell, \& Kelley, 2011; Svetlova, Nichols, \& Brownell, 2010) [30][31]. Due to the young age of the children in this stage, people need to adopt observation method. In order to collect a huge quantity of data regarding their prosocial behavior, we utilized questionnaire survey with grade- 5 and grade- 6 students as the research subject, for children in at those ages are situated in what Piaget called formal operational stage, and can read items independently without help. In addition, in respect with prosocial recognition and behavior, children at such stage can experience and express better for their recognition of parent-child interaction, gratitude, and prosocial behavior, so this research took grade- 5 and grade- 6 students as the research subject.

Based on the above, it can be concluded that the development of gratitude and prosocial behavior is affected by parent-child interaction and that gratitude affects prosocial behavior. Therefore, it can be deduced that parent-child interaction affects prosocial behavior through gratitude. Previous research has not examined the potential role of gratitude as a mediating variable in the relationship between parent-child interaction and prosocial behavior. Therefore, this study explored whether gratitude has a mediating effect on the relationship between parent-child interaction and prosocial behavior.

\subsection{Literature Review}

\subsubsection{Parent-Child Interaction Affects Prosocial Behavior}

According to the literature, parents have long-term, profound, and important effects on their teenage children's psychological, emotional, and behavioral problems. Robinson (2009) [32]referred to that socialization in the family is the starting point for influencing prosocial behavior. Kostelnik, Gregory, Soderman, and Whiren (2012) [33] also considered that parents' educational attitudes, modeling, award, explanation, cooperation and order will impact on children's development of prosocial behavior. Such arguments are supported by many scholars. For instance, Herschell et al (2003) [27] also supported that parent-child interactions affect prosocial behavior. Foster, Reese-Weber, 
and Kahn (2007) [34] believed that the demonstration of prosocial behavior by parents in their interactions with their children contributes to the development of this behavior by their children. Runyon and Deblinger (2013) [35]proposed that parents are the models for prosocial behavior, which is established through parent-child interactions.

Furthermore, empirical studies supported parent-child interaction affects prosocial behavior. As Lin (2000) [36] adopted group interview and semi-structure questions to interview 19 parents with 3-5 year-old children selected by early childhood educator and with "high prosocial tendency" in order to collect data involving children's prosocial development. It is found that many interviewed parents have prosocial behavior as well. They contribute generously and are public spirited, and their modeling influences on their children unconsciously. On the other hand, those parents keep in mind to remind their children to take prosocial behavior or share how they feel about prosocial behavior with children.

Parent-child interaction may differ between father and mother. On the basis of the results of meta-analysis conducted by Zaman and Fivush (2013) [37], it is found that in Europe and America, mother tends to use more supportive terms like encouragement and agreement in parent-child interaction. Besides, Attili, Vermigli, and Roazzi (2010) [38] conducted research for 34 Participants (7-9 years of age), examined links between parents' and children's interactive styles at home as well as children's social competence among peers, which were defined in terms of both prosocial, aggressive, and isolate behaviors and social success at school. It is found that Mother's negative interaction and disconfirming are correlative negatively with prosociality. Furthermore, there are little association between fathers' interaction and children's social competence. In Taiwan, mother is the main carer of children in elementary stage, so the parent-child interaction may vary. In Chiang's (2007) [39]research, with 1095 grade-4 to 6 students in Taiwan as subject, he analyzed relationship between elementary school students' family leisure activities, parent-child interaction, and interpersonal relationship. The results showed that children's interaction with mother is superior to father. Consequently, father and mother differ in respect with parent-child interaction, causing social competence differs correspondingly, so we separate social competence from parent-child interaction for discussion.

\subsubsection{Parent-Child Interaction Affects Prosocial Behavior}

As previously noted, the family is the first and most important social unit with whom children have contact. Parent-child interactions significantly affect the development of children's personality and social behavior. According to Bandura's (1977) [40] social learning theory, the interaction between parents and children involves both observation and learning and is the most important process in human socialization, rendering the parents the most important sources of information about appropriate behaviors. Moreover, Emmons, McCullough, and Tsang (2003) [41] believed that gratitude can be taught and learned. Thus, the verbal expression and teaching of gratitude by parents affect a child's cognitions and behaviors in this regard. For example, Seligman (2012) proposed that the cultivation of gratitude should start at home. Gordon (2013) also believed that parents can act as models for gratitude through parent-child interactions. In Greif and Gleason's (1980) [42] experiment, the research subject are 22 2-to-5-year-old boys and girls from and their parents. They designed routines for 'hi,' 'good-bye,' and 'thanks'. At the end of a parent-child play session, an assistant entered the playroom with a gift for the child for participating in the study to elicit politeness routines from the children. Parental prompting led $86 \%$ of the children to express gratitude, but with no prompting expressing gratitude became the least frequent politeness routine: only $7 \%$ of children spontaneously expressed gratitude.

From this perspective, there is a causal relationship between parent-child interaction and gratitude such that parent-child interaction acts as the cause and gratitude acts as the effect.

\subsubsection{Gratitude Affects Prosocial Behavior}

Gratitude is derived from the Latin word gratia that represents grace, graciousness, and gratefu1ness and implies kindness, generosity, gift, good of receiving and giving, and asking for no return (Emmons \& McCullough, 2003) [43]. Lazar and Lazarus (1994) [44] held that gratitude is a kind of empathic emotion; that is, when the individual receives certain profit, he or she can discern other people's contribution to himself/herself, and consider that other people provide a valuable, and altruistic help, so that the individual generates gratitude. Also, Watkins, Woodward, Stone, and Kolts (2003) [45] thought that individual with gratitude experiences sense of abundance, and appreciate the contribution of others to their well-being. He or she contributes benefit to others, and appreciates simple pleasure in life. After further experiencing gratitude, he also learn the importance of showing gratitude, which will motivate people to conduct prosocial behavior.

Next, McCullough et al (2001) [9] believed that gratitude is a kind of moral affect, the moral behavior triggered by gratitude involves helping others. Therefore, they posited that by experiencing gratitude, a person is motivated to carry out prosocial behavior.

Additionally, gratitude is a kind of positive emotions, as it can foster prosocial behavior (Mikulincer \& Shaver, 2010) [46]. McCullough and Tsang(2004) [47] also regarded that gratitude is a positive emotion that can enhance the relationship with the loved ones, and establish friendship and social networks as long-term personal resources. Based on the theory of social exchange, Emmons and Mishra (2011) [48] proposed that the positive emotions generated by partners in a social exchange lead to social cohesion that strengthens social networks. Therefore, prosocial behavior 
creates social resources, fosters trust, develops secure relationships, and facilitates social interactions. Such augment is consistent with what Fredrickson (2004) [49] proposed that broadens and builds theory of positive emotion. This theory claims that gratitude is characterized with positive emotions, and it can broaden the items of the individual's thinking and action, and build long-term social, intellectual, and physical resources. As a result, the individual with gratitude express gratitude by means of prosocial methods in order to maintain social relationship (Emmons \& Shelton, 2002) [50]. In Froh, Sefick, and Emmons's (2008) [51] research, they adopted 221 middle school students in grades 6 and 7 as the research subject, and the quasi-experimental design followed by randomly assigning 11 classes to 1 of 3 conditions (i.e., gratitude, hassles, and control). Four classes received the gratitude or hassles condition ( 8 classes total) and three classes served as no-treatment controls. Their experimental results also support this perspective.

In accordance with analysis discussed above, This study first analyzed the correlation between father-child and mother-child interactions. We found that parent-child interaction affects gratitude or prosocial behavior and that gratitude affects prosocial behavior. Thus, it can be deduced that parent-child interaction can affect prosocial behavior through gratitude. Nevertheless, the research in the past had not taken grade 5 and 6 students as the research subject to analyze the intermediate effect of gratitude on parent-child interaction and prosocial behavior. The most relevant study, conducted by Bartlett and DeSteno (2006) [52], found that gratitude mediated the relationship between em otions and helpfulness. Furthermore, the statistical method used in the past was the product-moment correlation, but pairwise correlations cannot identify mediating effects. Thus, this study adopted structural equation modeling (SEM), which includes residual error in the model and calculations, to produce a more accurate analysis. In conclusion, this study used parent-child interaction as the exogenous variable and prosocial behavior as the endogenous variable to analyze whether gratitude has a mediating effect on the relationship between these two variables.

\section{Research Design}

\subsection{Research Subjects}

This study examined fifth- and sixth-grade students at 241 public elementary schools in Kaohsiung City during the 2012 school year. Participants were selected using a cluster sampling technique in which the size of regional subsamples was determined by their relative contributions to the size of the entire student population. We extracted samples from randomly selected schools in each of the following districts: three from northern Kaohsiung, Fengshan, and Gangshan districts; two from southern Kaohsiung and Cishan districts; and one from central Kaohsiung district. According to 2013 Taiwan's Educational Fundamental Act, We then divided elementary schools into small (number of classes in the school less than 12), medium (number of classes in the school ranges 13-48), and large(number of classes in the school more than 49). According to Educational Bureau of Kaohsiung City, in school year of 2014, the upper limit of students in each class is 29 , the average of students in each class is 24.29 students extracted one fifth- and one sixth-grade class from each small and medium school; and extracted two fifth- and two sixth-grade classes from each large school to study entire classes. This study drew samples from 36 classes in 14 schools and distributed 1041 questionnaires. A total of 1026 questionnaires were returned, yielding a recovery rate of $98.6 \%$. After disregarding invalid (the same options, like all are 3) and incomplete questionnaires by listwise deletion method (delete the item when any is unanswered, except Parent-Child Interaction Scale), we analyzed data from a total of 987 valid questionnaires, which corresponded to a valid recovery rate of $96.2 \%$.

Among the samples, in regard of gender, there were 521 males $(52.8 \%), 466$ females $(47.2 \%)$; for grade level, there were 482 Grade 5 students $(48.8 \%$ ), and 505 Grade 6 students $(51.2 \%)$. Concerning number of children in the family, one is $128(12.9 \%)$, two is $584(59.2 \%)$, three is 209 $(21.2 \%)$, and four and more is $66(6.7 \%)$. For birth order, eldest is $383(38.8 \%)$, youngest is $392(39.7 \%)$, middle child is $96(9.7 \%)$, and only child is $116(11.8 \%)$, while type of family, big family (grandparents, parents, children, and other relatives live in the same building or as neighbors) is 173 $(17.5 \%)$, small family (parents live with children) is 479 $(48.6 \%)$, stem family (grandparents, parents, and children live together) is $175(17.7 \%)$, and single-parent family is 160 $(16.2 \%)$.

\subsection{Research Tools}

This study created the Parent-Child Interaction, Gratitude, and Prosocial Behavior Scales for students in the higher grades of elementary school. These instruments were based on the literature and subsequent refinements made by the authors. One of the authors is an elementary school teacher, and she came up with the draw of questionnaire based on literature and observation for student's school life. The participants rated how they agree with each item was for them along a 5-point scale ranging from " $1=$ disagree", " $2=\mathrm{a}$ little bit agree", " $3=$ partially agree", " $4=$ mostly agree" to "5=completely agree". The procedures described as below.

\subsubsection{Preparation}

\section{(1) Parent-Child Interaction Scale}

On compiling Parent-Child Interaction Scale, Lo and Chen(2005) [53] have compiled scale for elementary school students on the basis of the parent-child interaction frequency and intimacy degree, and there are four 
dimensions:

Frequent-Connection-and-MentalCohesiveness, indicating high parent-child interaction frequency, and are characterized with warmth, intimacy, support, and identification. The remaining three dimensions are Frequent-Connection-and-Mental-Incohesiveness, Infrequent-Connection-and-Mental-Cohesiveness, and Infrequent-Connection-and-Mental-Incohesiveness. After measuring with this scale, it is better to classify the interaction results into four types, not suitable for summing up the points. This study adopted the concept of parent-child interaction developed by Gongla and Thompson (1987) [1], who believed that parent-child interaction should include: A. Physical interaction, which refers to the communication and frequency of contact among family members. B. Psychological interaction, refers to the attachment among and identity of family members. The substance of such interactions is broad, including the amount of time spent by parents and children together, feelings, the content of dialogue, body language, communication behaviors, degree of care and intimacy, and parenting styles. We created scales based on Gongla and Thompson's conceptualization. After the pilot test $(N=224)$, frequency of interaction (which refers to the frequency of interactions between parents and children), content of interactions (which refers to physical contact and communication), and feelings of connection (which refers to psychological feelings) were used as dimensions to assess parent-child interaction. Higher scores on these three dimensions reflect better parent-child interaction.

\section{(2) Gratitude Scale}

Lin and Yeh (2011)[36] developed for the undergraduates in Taiwan the Inventory of Undergraduates' Gratitude, which extracted five factors-- thanks others, thanks God, cherish what you have, appreciate the hardship, and appreciate the moment. However, the scales above did not made for grade 5 and 6 students. Besides, McCullough et al(2002) [6] proposed that positive experiences enable individuals to identify the help provided by others and the generosity reflected in the help of others. Moreover, although there is a general tendency to react with general heartfelt gratitude, the inclusion of a third person in an interaction can lead to a negative experience. Thus, this study included positive cognitions related to gratitude (cognitions arising from positive experiences), negative cognitions related to gratitude (cognitions related to negative experiences), and behaviors related to gratitude (language or actions used to express gratitude to another person) as the three dimensions of gratitude and developed the questionnaire according to this definition. Higher total scores on these three dimensions reflect higher levels of gratitude.

\section{(3) Prosocial Behavior Scale}

There are numerous ways to behave prosocially. For example, Elementary School Children's Prosocial Behavior Scale designed by Taiwan scholar Lo (1998) [54] has dimensions including Sharing, Helping, cooperation, comforting, taking care, and giving, but it was made 17 ago. In addition, Eisenberg (1982) [55] believed that prosocial behaviors include comforting, sharing, and helping. Furman (2011) [56] proposed that sharing, comforting others, donating, volunteering, and helping others are types of prosocial behavior. These studies showed that there are numerous ways to show prosocial behavior. Marion (2003) [57] claimed that prosocial behaviors can be grouped into three distinct categories: sharing (dividing up or bestowing), helping (acts of kindness, rescuing, removing distress), and cooperation (working together to reach a goal), and Wentzel (2014) [58] also noted that prosocial behavior in the form of sharing, helping, and cooperating is a hallmark of social competence during children. Furthermore, this viewpoint also treats the age and ability of higher-level elementary school students to share, help others, and cooperate as dimensions of prosocial behavior. Higher total scores on these three dimensions are indicative of higher levels of prosocial behavior.

\subsubsection{Results of the Pilot Test}

The four self-developed scales were subjected to the following three procedures to evaluate the psychometric properties: 1. item analysis, whereby items with critical values greater than 3 were identified, the $t$ value of Parent-child Interaction Scale (interaction with mother) ranges between 85.36 to 14.19 , that of Parent-child Interaction Scale(interaction with father) between 5.21-16.00, Gratitude Scale between 7.97-15.69, and Prosocial Behavior Scale between 8.79-13.90, showing that all items have discrimination. 2. factor analysis, which first involved calculation of the Kaiser-Meyer-Olkin measure of sampling adequacy (standard value>.80) and the performance of Bartlett's Spherical Test (standard value $p<.05$ ) and then involved adding rotation to the items with the greatest variance, selecting those with an initial eigenvalue greater than 1 as factors, and selecting factors with factor loadings greater than .30. The analysis results are: four scales meet the standard, among which Parent-child Interaction Scale with Mother, and with father extracted $3 \mathrm{f}$ actors, respectively---Frequency of interaction (4 items, e.g. Mom often took me out for a trip on vacation.), Content of interaction ( 5 items, e.g. I often confide myself to Mom about my inner feelings.), Feeling of connection (5 items, e.g. With Mon, I feel warm and satisfactory.), and the total explanatory value are $66.30 \%$ and $65.68 \%$. Gratitude Scale extracted three factors-- Positive cognitions regarding gratitude (5 items, e.g. I should appreciate my families' devotion to our family.), Negative cognitions regarding gratitude (4 items, e.g. The blame from families aims to help me do things better.), a and Behavior of regarding gratitude (4 items, e.g. On special days, I will send cards or gifts to those who I want to appreciate, such as family members, teachers and classmates.), and the Total explanatory value is 70.28\%. Prosocial Behavior Scale also extracted three 
factors-- Sharing (5 items, In group activity, I will participate in group discussion, and exchange ideas with my classmates.), Helping others (4 items, e.g. When my classmate perform poorly, I always encourage him/her to try harder next time.), Cooperation (4 items, e.g. I will actively invite the classmates to carry out the activity together.), and the total explanatory value is $70.68 \%$. 3 . reliability analysis, which the factors chosen have a reliability greater than .60 and an overall value greater than .80. It is found that: for Parent-child Interaction Scale (interaction with mother), the total reliability is .88 , Parent-child Interaction Scale (interaction with father) is .89, Gratitude Scale is .92, and Prosocial Behavior Scale's Total reliability is .92. The detailed results are shown in Table 1.

Table 1. Reliability and validity of scales

\begin{tabular}{|c|c|c|c|c|c|c|}
\hline \multirow[b]{2}{*}{ Factor } & \multirow[b]{2}{*}{ Question no. } & \multicolumn{2}{|c|}{ Validity } & \multirow[b]{2}{*}{ Reliability } & \multirow{2}{*}{$\begin{array}{c}\text { Total } \\
\text { explanatory } \\
\text { value }(\%)\end{array}$} & \multirow[b]{2}{*}{$\begin{array}{c}\text { Total } \\
\text { reliability }\end{array}$} \\
\hline & & $\begin{array}{l}\text { Factor } \\
\text { loading }\end{array}$ & $\begin{array}{c}\text { Explanatory value } \\
\text { after transformation } \\
(\%)\end{array}$ & & & \\
\hline \multicolumn{7}{|c|}{ Parent-child Interaction Scale(interaction with mother) } \\
\hline Frequency of interaction & 4 & $.53-.72$ & 18.57 & .77 & 66.30 & .88 \\
\hline Content of interaction & 5 & $.50-.82$ & 22.86 & .86 & & \\
\hline Feeling of connection & 5 & $.49-.89$ & 24.87 & .87 & & \\
\hline \multicolumn{7}{|c|}{ Parent-child Interaction Scale (interaction with father) } \\
\hline Frequency of interaction & 4 & $.66-.79$ & 17.53 & .75 & 65.68 & .89 \\
\hline Content of interaction & 5 & $.65-.86$ & 22.96 & .88 & & \\
\hline Feeling of connection & 5 & $.75-.87$ & 25.17 & .88 & & \\
\hline \multicolumn{7}{|c|}{ Gratitude Scale } \\
\hline $\begin{array}{l}\text { Positive cognitions regarding } \\
\text { gratitude }\end{array}$ & 5 & $.61-.85$ & 28.51 & .89 & 70.28 & .92 \\
\hline $\begin{array}{l}\text { Negative cognitions regarding } \\
\text { gratitude }\end{array}$ & 4 & $.61-.83$ & 23.18 & .83 & & \\
\hline Behavior of regarding gratitude & 4 & $.53-.82$ & 18.59 & .80 & & \\
\hline \multicolumn{7}{|c|}{ Prosocial Behavior Scale } \\
\hline Sharing & 5 & $.76-.85$ & 29.53 & .93 & 70.68 & .92 \\
\hline Helping others & 4 & $.66-.81$ & 20.87 & .80 & & \\
\hline Cooperation & 4 & $.64-.81$ & 20.28 & .83 & & \\
\hline
\end{tabular}

Note: $N=224$ 


\subsection{Data Processing and Analysis}

\subsubsection{Model Fit}

This study used Analysis of Moment Structures, edition 7.0 (Amos 7.0) to determine correlations among the three potential variables: parent-child interaction, gratitude, and prosocial behavior. There are many methods for testing the model fit index. In this case, the overall model fit was divided into three parts: 1 . The absolute fit index, for which this study adopted the minimum fit function chi-square $\left(\div^{2}\right)$, root mean square error of approximation (RMSEA), goodness-of-fit index (GFl), and adjusted goodness-of-fit index (AGFl); 2.The adjusted fit index, for which this study adopted the normed fit index (NFI), non-normed fit index (NNFI), comparative fit index (CFI), and incremental fit index (IFI). The standard values for these should all be greater than .90 .

\subsubsection{Model Estimation}

This study used a product-moment correlation matrix to perform estimations and adopted a normal distribution to estimate the maximum likelihood method.

\subsubsection{Missing Values}

SEM cannot involve missing values, but 160 respondents, accounting for $16.20 \%$ of the entire sample, were members of single-parent families, and this study explored father-child and mother-child interactions separately. According to Kline (1998), there are three ways to deal with the missing data: (1) to delete them, (2) to replace (impute) the missing data with estimated scores and (3) to model the distribution of missing data and estimate them based on certain parameters. Therefore, imputation was used to replace the missing values.

\subsection{Model and Hypotheses}

\subsubsection{Model}

Based on the aforementioned theoretical considerations, the following hypothetical model was examined by this study, shown in Figure 1.

\subsubsection{Hypotheses}

H1: Father-child and mother-child interactions will be significantly correlated.

$\mathrm{H} 2$ : Gratitude will have a mediating effect on the relationship between father-child interaction and prosocial behavior.

H3: Gratitude will have a mediating effect on the relationship between mother-child interaction and prosocial behavior.

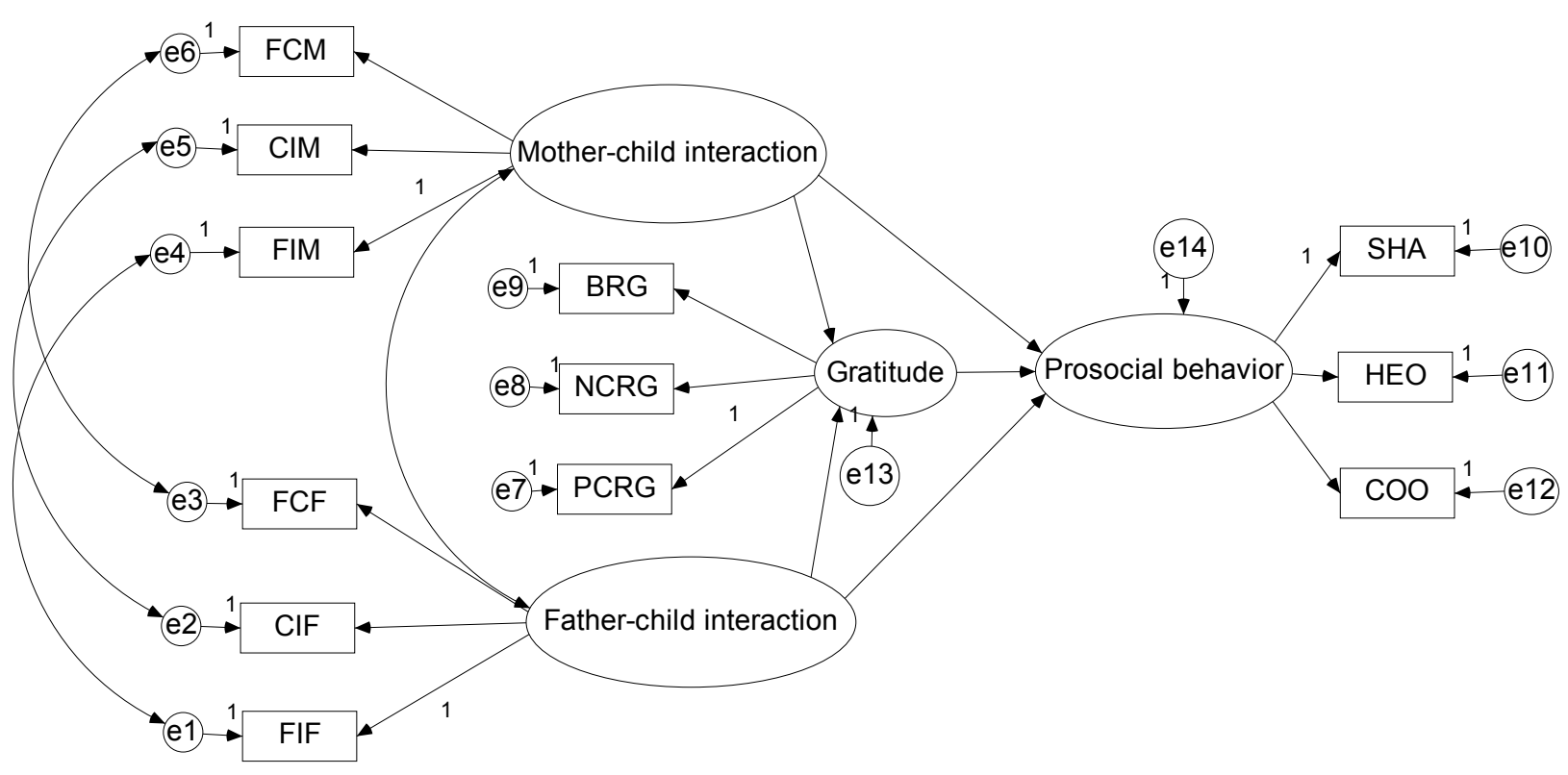

Note: FIF $=$ Frequency of interaction of the father; $C I F=C$ Content of interaction of the father; $F C F=F e e l i n g$ of connection of the father; FIM=Frequency of interaction of the mother; $\mathrm{CIM}=$ Content of interaction of the mother; $\mathrm{FCM}=$ Feeling of connection of the mother; $\mathrm{PCRG}=\mathrm{Positive}$ cognitions related to gratitude; $\mathrm{NCRG}=$ Negative cognitions related to gratitude; $\mathrm{BRG}=$ Behavior related to gratitude; $\mathrm{SHA}=$ Sharing; $\mathrm{HEO}=\mathrm{Helping}$ others; $\mathrm{COO}=\mathrm{Cooperation}$.

Figure 1. Hypothetical Model 


\section{Results and Discussion}

\subsection{Correction Analysis}

Overall, The product-moment correlation coefficient of the three potential variables were.17-.67(Table 2).

Table 2. Descriptive statistics and product-moment correlations of parent-child interaction, gratitude, and prosocial behavior

\begin{tabular}{|c|c|c|c|c|c|c|c|c|c|c|c|c|}
\hline & \multicolumn{3}{|c|}{ Father-child interaction } & \multicolumn{3}{|c|}{ Mother-child interaction } & \multicolumn{3}{|c|}{ Gratitude } & \multicolumn{3}{|c|}{ Prosocial behavior } \\
\hline & 1 & 2 & 3 & 4 & 5 & 6 & 7 & 8 & 9 & 10 & 11 & 12 \\
\hline 1. FIF & 1 & & & & & & & & & & & \\
\hline 2. CIF & .60 & 1.00 & & & & & & & & & & \\
\hline 3. FCF & .40 & .52 & 1.00 & & & & & & & & & \\
\hline 4. FIM & .62 & .39 & .24 & 1.00 & & & & & & & & \\
\hline 5. CIM & .38 & .67 & .35 & .60 & 1.00 & & & & & & & \\
\hline 6. FCM & .17 & .28 & .64 & .36 & .48 & 1.00 & & & & & & \\
\hline 7. PCRG & .20 & .28 & .28 & .29 & .42 & .40 & 1.00 & & & & & \\
\hline 8. NCRG & .19 & .33 & .33 & .25 & .39 & .37 & .67 & 1.00 & & & & \\
\hline 9. BRG & .19 & .26 & .24 & .29 & .38 & .34 & .66 & .64 & 1.00 & & & \\
\hline 10. SHA & .22 & .28 & .25 & .29 & .33 & .28 & .55 & .48 & .52 & 1.00 & & \\
\hline 11. HEO & .24 & .31 & .23 & .30 & .34 & .23 & .54 & .54 & .62 & .62 & 1.00 & \\
\hline 12. $\mathrm{COO}$ & .19 & .24 & .23 & .33 & .32 & .31 & .49 & .46 & .55 & .61 & .61 & 1.00 \\
\hline$M$ & 15.03 & 17.30 & 21.63 & 15.82 & 18.75 & 22.18 & 22.50 & 16.49 & 16.37 & 20.76 & 14.82 & 16.38 \\
\hline$S D$ & 3.79 & 5.24 & 4.19 & 3.43 & 5.00 & 3.74 & 3.26 & 3.35 & 3.13 & 4.06 & 3.77 & 3.12 \\
\hline
\end{tabular}

Note:

1. $N=985$

2. The significance level of the correlation between two variables reached .001 .

3. $F I F=$ Frequency of interaction of the father; $C I F=C$ ontent of interaction of the father; $F C F=F e e l i n g$ of connection of the father; FIM=Frequency of interaction of the mother; $\mathrm{CIM}=$ Content of interaction of the mother; $\mathrm{FCM}=$ Feeling of connection of the mother; $\mathrm{PCRG}=\mathrm{Positive}$ cognitions related to gratitude; $\mathrm{NCRG}=$ Negative cognitions related to gratitude; $\mathrm{BRG}=$ Behavior related to gratitude; $\mathrm{SHA}=$ Sharing; $\mathrm{HEO}=\mathrm{Helping}$ others; $\mathrm{COO}=\mathrm{Cooperation}$.

\subsection{Analysis of the Mediating Variable}

\subsubsection{Offending Estimate test}

We processed a preliminary evaluation for basic fitness, and discover what listed below. The result are: in the element of matrix $\Theta_{\varepsilon}$, the tolerant variances from $\varepsilon_{1}$ to $\varepsilon_{12}$ are all positive are all positive. 2. Parameter standard errors are from .04 to .17, there is not a big one. 3.) Latent variables and the factor loading $\ddot{e}_{1}-\ddot{\mathrm{e}}_{12}$ among its measurement indicators are from .63 to .87 . And this meets the standard to be more than .50 and less than .95 .

Based on above analysis, the test result has met the assumption, so it means the basic fitness is a good one. Therefore, there is no offending estimation (And it means all output data are in an acceptable range).

\subsubsection{Analysis of the Overall Goodness of Fit of the Hypothetical Model}

The results related the overall goodness of fit of the hypothetical model are shown in Figure 2.

According to the results of the overall goodness-of-fit analysis, the value of $\chi^{2}=149.09$, reached the level of significance. This might be because the research path was incomplete, the model needs revision, or the sample was too large. Second, a RMSEA $=.05$, value less than .08 means that the hypothetical model is good. AGFI=.97, GFI=.98,A higher AGFI and GFI reflect a better fit; the standard value is .90. The NFI assumes that the difference between the chi-square values of the hypothetical model and those of the null hypothesis represents the extent to which the hypothetical model constitutes an improvement over the worst model. The standard value for NFI is .90 , and it reached a value of .98 in this study, indicating that our hypothetical model can be assumed to have a better fit than an independent model. The effect of the complexity of the NNFI on the model was considered, but it was not affected by the size of the sample. The standard value for the NNFI is .90, and it reached a value of .98 in this study, indicating that the fit of our model is good and does not need to be reset. The CFI of this study was .98 , showing that the degree to which our model is superior to a stand-alone model with no covariation relationship is within an acceptable range. In addition, IFI values closer to 1 indicate that the model is more relevant. The IFI of this study was .98 . In conclusion, the results of the overall fit index analysis showed that the data in this study were appropriate.

\subsubsection{Model Parameter test}

In this model. there are four latent variables like parent-child interaction of fathers (See Fig. 2), and factor loading between latent variables and indicators ranges between .63-.87, $R^{2}$ (Individual reliability) ranges between.40-.75, with the standard value is .50 . Here, only indicators for Feeling of connection of the father and feeling of connection of the mother do not conform. 


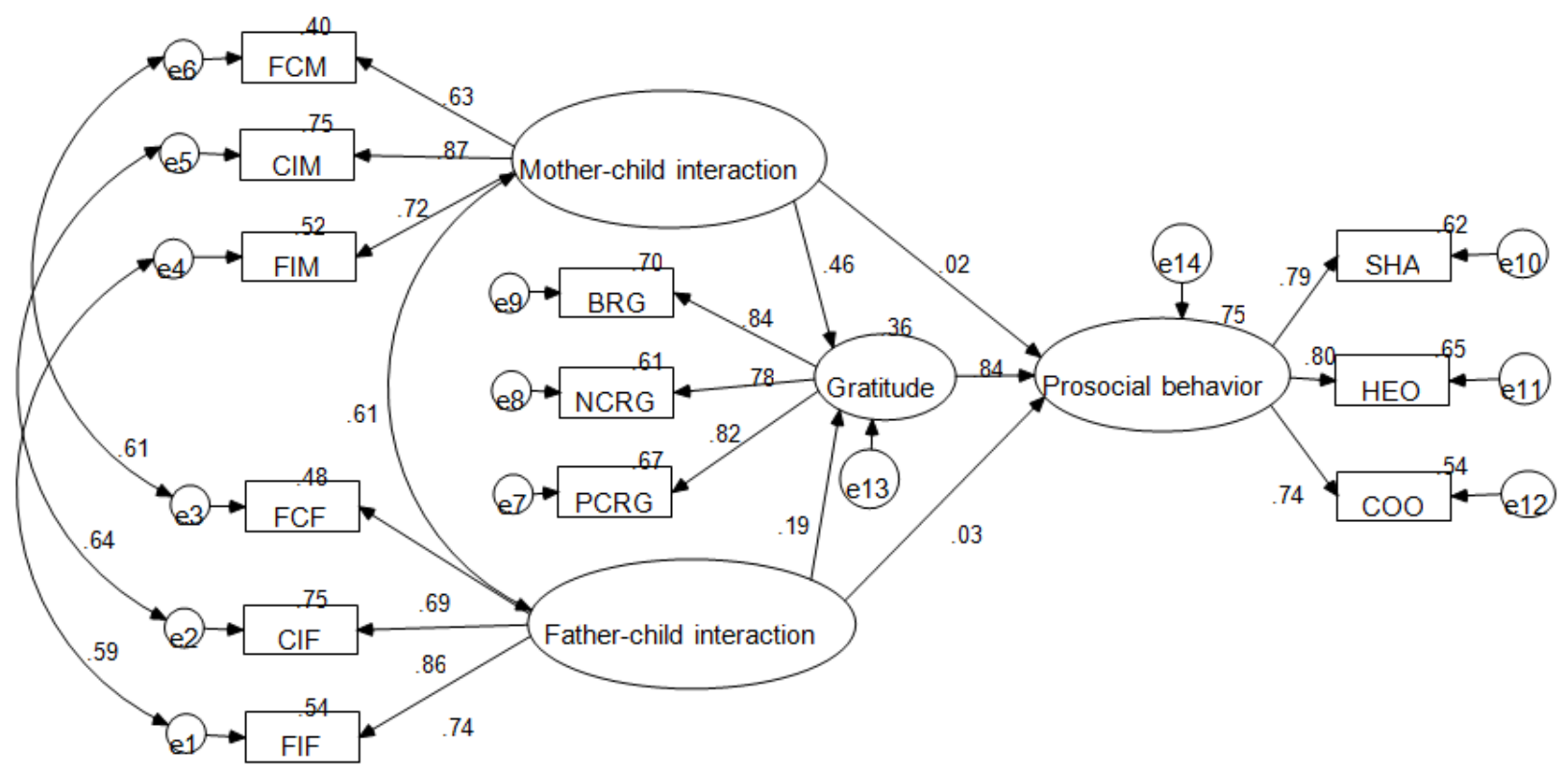

Note:

1. $N=985$

2. $\mathrm{FIF}=$ Frequency of interaction of the father; $\mathrm{CIF}=\mathrm{Content}$ of interaction of the father; $\mathrm{FCF}=\mathrm{Feeling}$ of connection of the father; FIM=Frequency of interaction of the mother; $\mathrm{CIM}=$ Content of interaction of the mother; $\mathrm{FCM}=$ Feeling of connection of the mother; $\mathrm{PCRG}=\mathrm{Positive}$ cognitions related to gratitude; $\mathrm{NCRG}=$ Negative cognitions related to gratitude; $\mathrm{BRG}=\mathrm{Behavior}$ related to gratitude; $\mathrm{SHA}=$ Sharing; $\mathrm{HEO}=$ Helping others; $\mathrm{COO}=\mathrm{Cooperation}$.

Figure 2. Path of the Hypothetical Model (standard solution)

\subsubsection{Analysis of Hypothetical Model}

In this model. there are four latent variables like parent-child interaction of fathers (See Fig. 2), and factor loading between latent variables and indicators ranges between .63-.87, $R^{2}$ (Individual reliability) ranges between $.40-.75$, with the standard value is .50 . Here, only indicators for Feeling of connection of the father and feeling of connection of the mother do not conform.

\section{(1) Parent-child interaction of fathers and mothers}

Consistent with our model, father-child and mother-child interactions were significantly correlated with one another, with coefficients ranging between .63 and .66 (Figure 2 and Table 1), and the variances between the two paths reached the significance level. Thus, the first hypothesis, "that father-child and mother-child interactions are significantly correlated," was supported, indicating that the interactions of fathers and mothers with children are positively correlated with each other. That is, the frequency and content of interactions and the feelings of connection with mothers and fathers are consistent.

\section{(2) Direct and indirect effects}

The hypothetical model treated gratitude as the mediating variable, and these results are presented in Figure 2. The direct and indirect effects were analyzed in terms of two paths:

A. The mediating effect of gratitude on the relationship between father-child interaction and prosocial behavior.
The path coefficient of the effect of father-child interaction on gratitude was .17 (estimated value $=.16$, standard error $)=.04$, critical value $=3.73, p<.001$ ). The path coefficient of the effect of gratitude on prosocial behavior was .84 (estimated value $=1.00$, standard error $=.06$, critical value $=18.03, p<.001)$. The variances of the two paths reached significance. The value obtained by multiplying the coefficients of the two paths was .14, which reflects a mediating effect. The correlation coefficient for the direct effect of gratitude on the relationship between father-child interaction and prosocial behavior was .03 (estimated value $=.04$, standard error $=.04$, critical value $=.88, p<.38$ ). The mediating value was higher than the direct-effect value, indicating the presence of a mediating effect. Moreover, the variance of the direct effect did not reach significance, indicating a full mediating effect. Meanwhile, bootstrapping with confidence intervals was used to examine significance of indirect effects, and the result showed $p=.002$, which means that the mediating effect of gratitude reaches significant level.

The mediating-effect coefficient refers to the original significant correlation between the direct relationships of the exogenous variable, the endogenous variables, and the mediating variable. However, after adding the mediating variable to the equation, the effect of the exogenous variable on the endogenous variable was reduced and became insignificant (Baron \& Kenny, 1986). The Pearson' product-moment correlation coefficient in Table 2 shows that the relationship between these variables was significant, and the subsequent SEM analysis treating father-child 
interaction and prosocial behavior as latent variables showed a correlation of .45 (estimated value $=.51$, standard error $=.05$, critical value $=11.29, p<.001)$. Thus, the original significant effect of father-child interaction on prosocial behavior was reduced when gratitude was added to the analysis.

B. The mediating effect of gratitude on the relationship between mother-child interaction and prosocial behavior.

The path coefficient of the effect of mother-child interaction on gratitude was .49 (estimated value $=.53$, standard error $=.05$, critical value $=10.20, p<.001)$. The path coefficient of the effect of gratitude on prosocial behavior was .84 (estimated value $=1.00$, standard error $=.06$, critical value $=18.03, p<.001)$. The variances of the two paths reached significance. The value obtained by multiplying the coefficients of the two paths was .41 , which reflects a mediating effect. The direct-effect value was .01 , and the variance of the two paths did not reach significance (estimated value $=.02$, standard error $=.05$, critical value $=.32$, $p<.75$ ), indicating a full mediating effect. Meanwhile, bootstrapping with confidence intervals was used to examine significance of indirect effects, and the result showed $p=.002$, which means that the mediating effect of gratitude reaches significant level.

The SEM analysis treating mother-child interaction and prosocial behavior as latent variables showed a correlation of .54 (estimated value $=.69$, standard error $=.05$, critical value $=13.02, p<.000$ ) between these variables. Thus, the inclusion of gratitude reduced the effect of mother-child interaction on prosocial behavior. Thus, hypothesis 3 , that "gratitude has a mediating effect on the relationship between mother-child interaction and prosocial behavior," was supported.

\subsubsection{Discussion}

These results support hypotheses 2 and 3, indicating that gratitude had a full mediating effect, as represented by the "father-child interaction-gratitude-prosocial behavior" and "mother-child interaction-gratitude-prosocial behavior" paths. These are discussed below

First, the path involving parent-child interaction and gratitude reflected a significant positive correlation. This finding is consistent with Bandura's social cognitive theory, which holds that parents are models for children, who observe and imitate their every word or action. In addition, the family is the first social group with which an individual has contact, and it is the influential social unit for an individual. Indeed, the interactions among family members, including those between parents and children, cannot be replaced by those within other types of social group. Indeed, the parent-child relationship has a major impact on the development of personality and social behavior. Parents' behavioral and verbal demonstrations of, and lessons about, gratitude affect children's cognitions and behaviors in this regard. This study confirmed the perspectives of Seligman (2012) [8] and Gordon (2013) [26], who believed that parent-child interaction can cultivate behavior reflective of gratitude in children. In addition, the paths of the effects of father-child and mother-child interactions on gratitude were both significant but reflected different levels of intensity. The coefficient associated with the father-child path is considered low, whereas that associated with the mother-child path is considered medium. This shows that mothers are the primary instructors with regard to gratitude.

Second, gratitude and prosocial behavior were strongly positively correlated, which supports the perspective advanced and the research conducted by McCullough, et al(2002) [6], Emmons and McCullough (2003) [43], and Froh and Bono (2008) [59], who believed that gratitude and prosocial behavior are positively correlated. That is, they believed that those who are more grateful are characterized by more empathy, forgiveness, and helpfulness. In addition, to cut in from Chinese cultural tradition, it was also pointed out that gratitude is the fundamental value faith as well as fundamental moral principle (Zhang, 2008) [7], and benevolence is the core behavior (Wen, 1989) [5]. As McCullough, et al indicated, gratitude is a function of the perception of intentional benevolence. Since children in Taiwan are taught that "helping others is the origin of happiness", it can be understood that why Taiwan children's gratitude has positive correlation with prosocial behavior.

Third, according to the literature, parent-child interaction affects gratitude and prosocial behavior, but this study found that gratitude plays a mediating role in the relationship of the other two variables. Runyon and Deblinger (2013) [35] and Foster et al (2007) [34] believed that parent-child interaction and prosocial behavior were positively correlated. However, those studies may ignore gratitude's mediating effect. When gratitude was added as a mediating variable, the relationship between the two other variables was reduced to almost zero, indicating that parent-child interaction does not affect prosocial behavior without the mediation of gratitude, irrespective of the strength of the correlation between such interaction and behavior. Although in accordance with Bandura's (1977) [40] theory of social learning, parents serve as "the important other" for children. From modeling, principling, guiding, leading, parents' expression of prosocial behavior does help children's development, what matters the most is that in parent-child interaction, parents show gratitude behavior through body language, facial expression, smiling, praise, and verbal instruction, which would naturally influences children's inner recognition and behavior. Just as Emmons and McCullough (2003) revealed, the person who realizes essence of gratitude will be able to help others.

\section{Research Limitation}

With research subject of grade 5 and 6 students, this research analyzed gratitude's mediating effect in parent-child interaction and prosocial behavior. Due to limit to research subject of only two grades, the generalization of the results is also applicable to the two grades. As for whether students in 
other grade are applicable, it still needs consideration. It is also recommended that the subsequent researchers can exert students in other grade for further exploration to verify the mediating effect of gratitude.

In addition, Tsang (2006) [60] asserted that much research on gratitude uses scenario and self-report methods, which introduce potential limitations of social desirability and low psychological realism. The current experiment addresses these limitations by pairing a laboratory induction of gratitude with behavioural and self-report measures of gratitude. In this research, questionnaire survey was used, so what affects prosocial behavior can only be deducted from literature or the researchers' generalization. Therefore, if interview can be used, we will be able to understand the reasons why gratitude has mediating effect between parent-child interaction and prosocial behavior.

\section{Conclusions}

We subjected our hypothetical model to SEM analysis. According to the overall goodness-of-fit analysis, all indices other than the chi-square value (i.e., the RMSEA, AGFI, GFl, NFI, NNFI, CFI, and IFI values) conformed to the standard values, indicating the appropriateness of the data obtained from our sample. Moreover, our data indicated the following: (1) Father-child and mother-child interactions were moderately correlated, and both the direction and the extent of this correlation were consistent with the hypothetical model. (2) Parent-child interaction and gratitude were positively correlated; consistent with our hypothetical model, each interaction was correlated with gratitude. However, the effects of interaction with fathers differed from those of interaction with mothers, and the relationship between each type of interaction and gratitude also differed. The path coefficient for father-child interaction reflects a weak positive correlation, whereas that for mother-child interaction reflects a moderately positive correlation. (3) Gratitude and prosocial behavior were strongly positively correlated, which is consistent with our literature review. Thus, this study also confirmed the correlation predicted by the hypothetical model. Moreover, our results are in agreement with those of previous research and are reflective of a strong correlation. (4) Gratitude had a complete mediating effect on the relationship between parent-child interaction and prosocial behavior. This study found that gratitude completely mediated the relationship between parent-child interaction and prosocial behavior. Furthermore, when only father-child or mother-child interaction was included in the SEM, each showed a separate significant relationship with prosocial behavior. These data reflect the originally significant correlations that disappeared after gratitude was added to the analyses as a mediating variable.

To sum up, we suggest that in practical practice: parents should model and show more grateful behavior to enhance prosocial behavior. It is found in this research that gratitude can completely mediate the relationship between parent-child interaction and prosocial behavior. In other words, if the child does not have recognition and behavior of gratitude, it will be less possible for prosocial behavior to take place. Therefore, parents should model and show more grateful behavior. For example, to model and express "thanks for families' devotion to family", "thanks for those make contributions to society silently", "thanks for those who have helped me", "in facing others' blame and correction, or even frustration, I must maintain grateful", "thanks for children's help", and "giving a gift or card to family, senior, or teacher in special days".

In the research in the future, we recommend to exert other variables as extraneous variables, because to view from coefficient of path for parent-child interaction and gratitude, father is .17 , and mother is .46 . When it is replaced by coefficient of determination, $r^{2}$, it is $11.90 \%$ and $21.16 \%$, showing that in regard of parent-child interaction for gratitude, there is still $89.10 \%$ and $78.84 \%$, which cannot be decided by parent-child interaction, and may be affected by other factors. For example. in Bartlett and DeSteno's (2006) [52]study, it is found that gratitude is the mediating variable of emotions and behavior of helping others. Consequently, in the future, research can be proceeded with other gratitude related variable to serve as extraneous variable.

On the other side, the background variables may influence prosocial behavior. For instance, in respect with gender, McMahon, Wernsman, and Parnes (2006) [61], and Padilla - Walker, Fraser, Black and Bean (2015) [62] found that gender in prosocial behavior reaches significant difference. However, Lai, Siu and Shek (2015) [63] adopted Chinese adolescents in Hong Kong as research subject, and they found no difference. Also, age in Gross et al's (2015) [64] study and family's socio-economic position in Guinote, Cotzia, Sandhu and Siwa's (2015) study have critical impact on the result variable, "prosocial behavior". Therefore, it is suggested the studies in the future include the background variables into the study to serve as the control variables.

\section{REFERENCES}

[1] P. A. Gongla, E. H. Jr. Thompson. Single-parent families. In M. B. Sussman \& S. K. Steinmetz(Eds.), Handbook of marriage and the family(pp. 397-418). Plenum Press, New York, 1987.

[2] H. J. Jeon, C. A. Peterson, J. DeCoster. Parent-child interaction, task-oriented regulation, and cognitive development in toddlers facing developmental risks. Journal of Applied Developmental Psychology, Vol.34, No. 6, 257-267, 2013

[3] M. Pocock, D.Trivedi, W. Wills, F. Bunn, , J. Magnusson.. Parental perceptions regarding healthy behaviours for preventing overweight and obesity in young children: a systematic review of qualitative studies. Obesity Reviews, Vol. 11, No.5, 338-353, 2010.

[4] S. M. Suldo, S. A. Fefer. Parent-child relationships and well-being. In Research, Applications, and Interventions for 
Children and Adolescents (pp. 131-147). Springer, Doetinchem, Netherlands, 2013.

[5] C. I. Wen. Chinese values. Tongta, Taipei, Taiwan, 1989.

[6] M. E. McCullough, R. A. Emmons, J. Tsang. The grateful disposition: A conceptual and empirical topography. Journal of personality and social psychology, Vol. 82, 112-127, 2002.

[7] W. Y. Zhang. Analysis of gratitude education of contemporary college students. Journal of Nmgxia University: Humanities \& Social Sciences Edition, Vol. 30, No.4,179-182, 2008.

[8] M. E. P. Seligman. Flourish: A visionary new understanding of happiness and well-being. Simon and Schuster, New York, 2012.

[9] M. E. McCullough, S. D. Kilpatrick, R. A. Emmons, D. B. Larson. Is gratitude a moral affect? Psychological Bulletin, Vol. 127, 249-266, 2001.

[10] C. Peterson, M. E. P. Seligman. Character strengths and virtues: A handbook and classification. , American Psychological Association Washington DC, 2004.

[11] M. E. McCullough, S. D. Kilpatrick R. A. Emmons D. B. Larson. Is gratitude a moral affect? Psychological Bulletin, Vol. 127, 249-266, 2001.

[12] M. Y. Bartlett, P. Condon, J. Cruz, J. Baumann, D. Desteno. Gratitude: Prompting behaviors that build relationships. Journal of Cognition \& Emotion, Vol.26, No.1, 2-13, 2012.

[13] P. Tough. How children succeed. Random House, New York, 2013.

[14] N. M. Lambert, A.Veldorale-Brogan. Gratitude intervention in adolescence and young adulthood: A positive psychology perspective. In C. Proctor \& P. A. Linley (Eds.) Research, Applications, and Interventions for Children and Adolescents (pp. 117-128). Springer, Doetinchem, Netherlands, 2013.

[15] A. M. Wood, S. Joseph, J. Maltby. Gratitude predicts psychological well-being above the big five facets. Personality and Individual Differences, Vol.46, 443-447, 2009.

[16] G. C. Gonzaga, D. Keltner, E. A, Londahl, M. D. Smith. Love and the commitment problem in romantic relations and friendships. Journal of Personality and Social Psychology, Vol.81, 247-262, 2001.

[17] C. A. Lewis. Five day abbreviated intensive parent-child interaction therapy for families with preschool age children with disruptive behavior problems (Doctoral dissertation). University of Florida, Florida, 2011.

[18] A. Zisser, S. M. Eyberg. Parent-child interaction therapy and the treatment of disruptive behavior disorders. In J. R. Weisz \& A. E. Kazdin (Eds.), Evidence-based psychotherapies for children and adolescents( 2nd ed. pp. 179-193). Guilford Press, New York, 2010.

[19] N. Eisenberg, P. H. Mussen. The roots of prosocial behavior in children. Cambridge University Press, Cambridge, England, 1989.

[20] K. R. Wentzel. Prosocial behavior and peer relations in adolescence. In L. M. Padilla-Walker, \& G. Carlo(Eds.), Prosocial development: A multidimensional approach(pp. 178-200). Oxford University Press, New York, 2014.
[21] K. R. Wentzel. Peer relationships, motivation, and academic performance at school. In A, Elliot, \& C, Dweck(Eds.), Handbook of competence and motivation(pp. 279-296 ). Guilford, New York, 2005.

[22] K. R. Wentzel, S. Baker, S. Russell. Peer relationships and positive adjustment at school. In R, Gilman, E. S, Huebner, \& M. J. Furlong(Eds.), Handbook of positive psychology in schools (pp. 229-243). Routledge, New York, 2009.

[23] N. Eisenberg, A. Morris, B. L. McDaniel, T. L. Spinrad. Moral cognitions and prosocial responding in adolescence. In R. M. Lerner \& L. Steinberg(Eds.), Handbook of adolescent psychology (3rd ed.) John Wiley \& Sons, New York, 2009.

[24] E. R. Griese, E. S. Buhs. Prosocial behavior as a protective factor for children's peer victimization. Journal of youth and adolescence, Vol. 43, No.7, 1052-1065, 2014.

[25] N. Weinstein, R. M. Ryan. When helping helps: Autonomous motivation for prosocial behavior and its influence on well-being for the helper and recipient. Journal of Personality and Social Psychology, Vol. 98, No. 2, 222-244, 2010.

[26] P. Gordon. KIPS cradle: A blog about parenting assessment-Assessing parenting to develop: Social intelligence \& gratitude, 2013. Retrieved from http://comfortconsults.com/blog/bid/298971/Assessing-Pare nting-to-Develop-Social-Intelligence-Gratitude

[27] A. D. Herschell, E. J. Calzada, S. M. Eyberg, C. B. McNeil. Clinical issues in parent-child interaction therapy. Cognitive and Behavioral Practice, Vol. 9, No.1, 16-27, 2003.

[28] M. E. McCullough, M. B. Kimeldorf, A. D. Cohen. An adaptation for altruism the social causes, social effects, and social evolution of gratitude. Current directions in psychological science, Vol. 17, No. 4, 281-285, 2008.

[29] J. R. Dunn, M. E. Schweitzer. Feeling and believing: the influence of emotion on trust. Journal of personality and social psychology, Vol. 88, No. 5, 736, 2005.

[30] K. Dunfield, V. A. Kuhlmeier, L. O. Connell, E. Kelley. Examining the diversity of prosocial behavior: Helping, sharing, and comforting in infancy. Infancy, Vol. 16, No.3, 227-247, 2011.

[31] M. Svetlova, S. R. Nichols, C. A. Brownell. Toddlers'prosocial behavior: From instrumental to empathic to altruistic helping. Child Development, Vol. 81, No. 6, 1814-1827, 2010.

[32] J. Robinson. Empathy and prosocial behavior. In Benson, J. B. \& Haith, M. M. (Eds.), Social and emotional development in infancy and early childhood (pp. 129-137). Academic Press, San Diego, CA, 2009.

[33] M. J. Kostelnik, K. M. Gregory, A. K. Soderman, A. P. Whiren. Guiding children's social development and learning. Wadsworth, Cengage Learning, Belmont, CA, 2012.

[34] P. A. Foster, M. Reese-Weber, J. H. Kahn. Fathers' parenting hassles and coping: Associations with emotional expressiveness and their sons socioemotional competence. Infant \& Child Development, Vol. 16, No.3, 277-293, 2007.

[35] M. K. Runyon, E. Deblinger. Combined parent-child cognitive behavioral therapy: An approach to empower families at-risk for child physical abuse. Oxford University Press, New York, 2013. 
[36] C. C. Lin, Y. C. Yeh. The development of the Inventory of Undergraduates' Gratitude. Psychological Testing, Vol. 58, No.S, 147-178, 2011.

[37] W. Zaman, R. Fivush. Gender differences in elaborative parent-child emotion and play narratives. Sex Roles, Vol. 68, No.9-10,1-14, 2013.

[38] G. Attili, P. Vermigli, A. Roazzi. Children's social competence, peer status, and the quality of mother-child and father-child relationships. European Psychologis, Vol. 15, 23-33, 2010.

[39] D. I. Chiang. The relationships between elementary school students' family leisure activities, parent-child interaction, and interpersonal relationship(Master thesis). National Kaohsiung Normal University, Kaohsiung, Taiwan, 2007.

[40] A. Bandura. Social learning theory. Prentice-Hall, EnglewoodCliff, NJ, 1977.

[41] R. A. Emmons, M. E. McCullough, J. A. Tsang. The Assessment of gratitude. In S. J. Lopez, \& C. R. Snyder(Eds.), Positive psychological assessment: A handbook of models and measures(pp. 327-341). American Psychological Association, Washington, DC, 2003.

[42] E. B. Greif, J. B. Gleason. Hi, thanks, and goodbye: More routine information. Language in Society, Vol. 9, 59-66, 1980.

[43] R. A. Emmons, M. E. McCullough. Counting blessings versus burdens: An experimental investigation of gratitude and subjective well-being in daily life. Journal of Personality and Social Psychology, 84, 377-389, 2003.

[44] R. S Lazarus, B. N. Lazarus. Passion and reason: Making sense of our emotions. Oxford University Press, New York, 1994.

[45] P. C. Watkins, K. Woodward, T. Stone, R. L. Kolts. Gratitude and happiness: Development of a measure of gratitude, and relationships with subjective well-being. Social Behavior and Personality: an international journal, Vol. 31, No. 5, 431-451, 2003.

[46] M. E. Mikulincer, P. R. Shaver. Prosocial motives, emotions, and behavior: The better angels of our nature. Washington, DC: American Psychological Association, 2010.

[47] M. E. McCullough, J. Tsang. Parent of the virtues? The prosocial contours of gratitude. In R.A. Emmons \& M.E. McCullough (Eds.), The psychology of gratitude (pp. 123-141). Oxford University Press, New York, 2004.

[48] R. A. Emmons, A. Mishra. Designing positive psychology: Taking Stock and moving forward. In Kennon, M. S., Todd, B. K., Michael, F. S. (Eds.), Why gratitude enhances well-being: What we know, what we need to know (pp. 248-262). Oxford University Press, USA, 2011.

[49] B. L. Fredrickson. The broaden-and-build theory of positive emotions. Philosophical transactions-royal society of London series b biological sciences, Vol. 359, 1367-1378, 2004.

[50] R. A. Emmons, C. M. Shelton. Gratitude and the science of positive psychology. Handbook of positive psychology, Vol.
$18,459-471,2002$.

[51] J. J. Froh, W. J. Sefick R. A. Emmons. Counting blessings in early adolescents: An experimental study of gratitude and subjective well-being. Journal of School Psychology, Vol. 46, No. 2, 213-233, 2008.

[52] M. Y. Bartlett, D. DeSteno. Gratitude and prosocial behaviour: Helping when it costs you. Psychological Science, Vol. 17, 319-325, 2006.

[53] P. H. Lo L. C. Chen. The study of family structure, parents-child interaction, emotional intelligence and interaction between peers for elementary students. Bulletin of Educational Psychology, Vol. 36, No. 3, 221-240, 2005.

[54] R. Y. Lo. (1998). The investigation of elementary school children's prosocial behavior and its related factors. Journal of Pingtung Teachers College, 11, 105-140.

[55] N. Eisenberg.. The development of reasoning regarding prosocial behavior. In N. Eisenberg(Ed.) The development of prosocial behavior(pp.219-249). Academic Press, New York, 1982.

[56] N. N. Furman. The effects of a treatment curriculum on the learning transfer of prosocial behavior in adventure education (Doctoral dissertation). The University of Utah, Utah, 2011.

[57] M. Marion. Guidance of young children. Merrill Prentice Hall, Columbus, OH, 2003.

[58] K. R. Wentzel. Prosocial Behavior and Peer Relations in Adolescence. In L. M. Padilla-Walker \& G. Carlo(Eds.), Prosocial development: A multidimensional approach (pp. 178-200). Oxford University Press, New York, 2014.

[59] J. J. Froh, G. Bono,. The gratitude of youth. In S. J. Lopez(Ed.), Positive psychology: Exploring the best in people(Vol.2, p.55-78). Greenwood, Westport, CT, 2008.

[60] J. Tsang. Gratitude and prosocial behaviour: An experimental test of gratitude. Cognition and Emotion, Vol. 20, 138-148, 2006.

[61] S. D. McMahon, J. Wernsman, A. L. Parnes. Understanding prosocial behavior: The impact of empathy and gender among African American adolescents. Journal of Adolescent Health, Vol. 39, No. 1, 135-137, 2006.

[62] L. M. Padilla - Walker, , A. M. Fraser, B. B. Black, R. A. Bean. Associations between friendship, sympathy, and prosocial behavior toward friends. Journal of Research on Adolescence, Vol. 25, No. 1, 28-35, 2015.

[63] F. H. Lai, A. M.Siu, D. T. Shek. Individual and social predictors of prosocial behavior among Chinese adolescents in Hong Kong. Frontiers in pediatrics, Vol., 3, 2015. Retrieved from http://www.ncbi.nlm.nih.gov/pmc/articles/P MC4432674/

[64] R. L. Gross, J. Drummond, E. Satlof-Bedrick, W. E. Waugh, M. Svetlova, C. A. Brownell. Individual differences in toddlers' social understanding and prosocial behavior: disposition or socialization?. Frontiers in Psychology, Vol. 6, 2015. 